\title{
Redes de deboche e excesso \\ Práticas performáticas no pós-pornô da América Latina
}

\author{
Networks of debauchery and excess: \\ Performative practices in Latin American post-porn
}

\section{Érica Ramos Sarmet ${ }^{1}$}

É roteirista, diretora e pesquisadora de cinema e audiovisual. Doutoranda em Meios e Processos Audiovisuais na ECA/USP com apoio da FAPESP, é Mestre em Comunicação (UFF) e Bacharel em Estudos de Mídia (UFF). Sua pesquisa de mestrado realizada com apoio da bolsa FAPERJ Nota 10 resultou na dissertação "Sin porno no hay posporno: corpo, excesso e ambivalência na América Latina" (2015), Menção Honrosa no Prêmio Compós de Teses e Dissertações 2016.

\section{Mariana Baltar}

Doutora em Comunicação pela UFF (2007), onde desenvolveu a tese "Realidade Lacrimosa - diálogos entre o universo do documentário e a imaginação melodramática". É professora da graduação em Cinema e Audiovisual da UFF onde desenvolve temas vinculados às políticas de gênero e sexualidade, bem como à dimensão do afeto e do excesso como estratégicas estéticas e matrizes culturais para dar conta do lugar do corpo, das sensações e emoções no contexto da cultura audiovisual contemporânea. É bolsista de produtividade do $\mathrm{Cnpq}(\mathrm{Pq} 2)$ e professora e vice-coordenadora do Programa de Pós-graduação em Cinema e Audiovisual (PPGCine) da UFF e coordenadora do Nex? Núcleo de Estudos do Excesso nas Narrativas Audiovisuais.

\section{RESUIMO}

Este artigo traz considerações sobre o movimento pós-pornográfico na América Latina, entendendo este campo como redes políticas que se estruturam a partir de performances não apenas nas obras, mas também em atuações cotidianas, como no uso de redes sociais. Tais redes acionam e agenciam disputas e discursos basilares das

1 Processo no 2019/10787-4, Fundação de Amparo à Pesquisa do Estado de São Paulo (FAPESP) 
pautas feministas e queer e colocam em cena, a partir do uso estético do deboche e do excesso, deslocamentos estético-políticos autorreflexivos e contra hegemônicos das convenções heterocisnormativas e raciais que tradicionalmente atravessam o campo da pornografia.

\section{PALAVRAS-CHAVE: Pós-pornografia; gênero; excesso; América Latina}

\section{ABSTRACT}

This article discusses "post-pornography" in Latin America, understanding this field as constituted by political networks that are structured based on performances not only in the material objects, but on a daily basis in performers and artists' online presence. These networks trigger and bring forward fundamental disputes and discourses of feminist and queer agendas, while, by means of the aesthetic use of mockery and excess, putting into play self-reflective and counter-hegemonic aesthetic-political displacements of heterocisnormative and racial conventions that are traditionally associated with pornography.

KEYWORDS: Post-porn; gender; excess; Latin America

\section{RESUMEN}

Este artículo trae consideraciones sobre el campo de la llamada postpornografía en América Latina, entendiendo este campo como redes políticas que se estructuran a partir de performances no solo en las obras, sino performances cotidianas, como en el uso de las redes sociales. Tales redes desencadenan y gestionan disputas y discursos fundamentales de las agendas feministas y queer, poniendo en escena, desde el uso estético del libertinaje y el exceso, desplazamientos estético-políticos autorreflexivos y contrahegemónicos de las convenciones heterocisnormativas y raciales que tradicionalmente transitan por la pornografía.

PALABRA CLAVE: Post-porno; género; exceso; America Latina

Dossiê Feminismos vitais - https://revistaecopos.eco.ufrj.br/

ISSN 2175-8689-v. 24, n. 1, 2021

DOI: 10.29146/ecopos.v24i1.27574 
Submetido em 15 de Agosto de 2020

Aceito em 27 de Maio de 2021

\section{Introdução}

“O problema nunca é a representação dos corpos, o problema é como esses corpos se tornam território e paisagem em frente à câmera" diz a personagem narradora do filme argentino As filhas do fogo (Albertina Carri, 2018). A voz off da personagem - uma cineasta que está retornando da Antártida - pontua a travessia das várias outras que se agregam pelo caminho desse road-movie pornô-lesbico-feminista, como definiu uma das críticas ao filme ${ }^{2}$. Esta obra é um bom começo de conversa sobre as questões a serem levantadas neste texto. A um só tempo, resume esteticamente as principais estratégias de apropriação feminista e queer dos procedimentos e repertórios do campo da pornografia - fazendo importantes deslocamentos políticos-estéticos - e congrega muitas das agentes das redes políticas e ativistas da chamada pós-pornografia latinoamericana, em performances que vão além do trabalho de atuação na obra, mas que se expandem para o gerenciamento de redes sociais das pornógrafas e o uso da internet como arena para uma construção dissidente que continuadamente imbrica obra, cotidiano e vida ativista. Deslocamento político dos repertórios estéticos e performance são dois mecanismos recorrentes que marcam a atuação das ativistas feministas e queer/kuir ${ }^{3}$ das redes pós-pornô da América Latina ${ }^{4}$.

2 MERTEN, Luiz Carlos. 'As filhas do fogo', de Albertina Carri, vai além do erotismo para representar o desejo feminino. O Estado de São Paulo, 20 de março de 2019. Disponível em: https://cultura.estadao.com.br/noticias/cinema,as-filhas-do-fogo-de-albertina-carri-vai-alem-doerotismo-para-representar-o-desejo-feminino,70002761418. Acesso em 02 de junho de 2020.

3 A escrita de "queer" como "cuir" ou "kuir" aparece cada vez mais frequentemente em trabalhos dedicados ao tema. Dentre as possibilidades de leitura que a grafia oferece, podemos listar a referência à fonética da palavra em sua gramática castelhana e brasileira como uma forma de reapropriação no contexto latinoamericano, bem como um modo de crítica e resistência à simples transposição de conceitos e termos eurocêntricos à realidade politica, social e cultural dos territórios latinoamericanos. Para uma discussão mais aprofundada sobre esse debate, cabe referenciar o texto do performer e crítico

Dossiê Feminismos vitais - https://revistaecopos.eco.ufrj.br/

ISSN 2175-8689 - v. 24, n. 1, 2021

DOI: 10.29146/ecopos.v24i1.27574 
As coreografias da voz e dos $\operatorname{corpos}^{5}$ em As Filhas do Fogo (nos seus intensos e sim, pornográficos encontros) falam não apenas de uma convocação à excitação, mas de uma ordem de problematizações que diz respeito à história do cinema, às formas de encenação do desejo, prazer e corpo femininos e à visibilidade de prazeres dissidentes, formas de vida e de estar junto. 0 filme de Albertina Carri não é sem precedentes no contexto recente das artes e política da América Latina. De certo modo, ele sintetiza um cenário que foi se delineando especialmente a partir de 2011, quando cada vez mais um circuito de redes ativistas começou a se articular e expandir, catalisado pelas trocas online ${ }^{6}$ e os encontros de mostras e festivais, fundamentados em ações intermidiáticas diversas, com destaque para performances e obras audiovisuais. Tais trocas levantam não apenas uma forma do fazer político em redes, mas expressam as potencialidades do fazer fílmico como catalisador de encontros de ordem afetiva e política (seja de corpos dentro do filme, seja do encontro entre corpo fílmico e corpo do espectador). Nesse sentido, a incorporação do topos do road-movie e os diálogos (cênicos ou extra fílmicos) com as redes estéticas e ativistas do pós-pornô argentino são vetores para trazer à visibilidade modos de vida, sexualidades e prazeres dissidentes.

de arte chileno Felipe Rivas San Martin, “Diga 'queer' con la lengua afuera: sobre las confusiones del debate latinoamericano" (2011) ou acompanhar as discussões reunidas no dossiê "Cinemas e audiovisualidades queer/kuir/cuir no Brasil e na América Latina", organizado por Dieison Marconi e Alessandra Brandão para a Rebeca - Revista Brasileira de Estudos de Cinema e Audiovisual (V. 9, número 2, 2020).

${ }^{4}$ É importante frisar que empregamos o termo "América Latina" de modo estratégico para analisar o movimento pós-pornográfico de regiões tão étnica, racial, histórica e culturalmente diversas como Argentina, Chile, Peru, México, Colômbia e Brasil. A proposição de pensar a produção pós-pornográfica latinoamericana parte de uma perspectiva de negociação dessa identidade estratégica, reconhecendo sua ficcionalidade colonial e entendendo que a articulação de um ativismo ao Sul atravessa limites geográficos e políticos.

${ }^{5}$ Usamos o termo coreografia de voz e de corpos para chamar atenção a aspectos dos gestos dos corpos em cena em relação ao corpo fílmico, seguindo uma perspectiva que aborda o cinema e audiovisual como uma interação sensorial e afetiva entre corpos em cena, corpo fílmico e corpo espectatorial. Tal abordagem se vinculada a teóricas como Vivian Sobschak (2004), Elena del Rio (2008) e Mariana Baltar (2018).

6 Por trocas online, referimo-nos aos sites de mostras e festivais, sites de artistas e coletivos, páginas e perfis em redes sociais como Facebook e Instagram, e eventos como lives, debates, palestras e exposições. A título de exemplo podemos referenciar a revista Hysteria (citada no artigo), o portal do projeto Porno Porsi, e seus perfis em plataformas de compartilhamento de vídeo como o vimeo (https://proyectopornoporsi.wordpress.com/; https://vimeo.com/user2377033); ou do coletivo Acento Frenético (http://www.acentofrenetico.tk/; https://vimeo.com/xxxacentofrenetico)

Dossiê Feminismos vitais - https://revistaecopos.eco.ufrj.br/

ISSN 2175-8689 - v. 24, n. 1, 2021

DOI: 10.29146/ecopos.v24i1.27574 
As filhas do fogo não segue uma estrutura tradicional, pelo contrário. Busca uma reescrita não só do road-movie clássico, mas também da estrutural usual das narrativas da pornografia. Em um movimento metalinguístico, a protagonista por diversos momentos narra em off a escrita do roteiro visto na tela, e do filme que ela própria está a fazer. Em uma dessas passagens, pergunta:

0 que eu narro quando narro pornografia? Deixar meu corpo sobre o relato, deixar o relato abrir sua boca, deixar o relato saciar a minha voracidade sobre o meu corpo condenado. Tem algo sobre o prazer que é irrepresentável, não há modos de criar uma verossimilitude.

A escolha das palavras, carregadas de visualidades e texturas, e o ritmo próprio da fala evocam carícias que contradizem o horizonte de expectativas que a pornografia mainstream usualmente forja, hegemonicamente pautada na centralidade da genitália, da penetração e do gozo como finalidade última. Quando faz esse tipo de procedimento, As filhas do fogo assume-se enquanto pornografia ao mesmo tempo que a questiona: assume nas muitas e intensas cenas de sexo explícito, mas também a questiona ao recusar e problematizar a ordem heterocisnormativa da penetração, explorando uma infinidade de coreografias de explosão erógena e orgástica com corpos e prazeres lésbicos não-normativos (embora, em sua quase totalidade, brancos e cisgêneros) e nãomonogâmicos.

Ao reconhecer e contestar, simultaneamente, o campo do pornográfico, o longa faz o que é talvez o grande salto definidor do chamado pós-pornô sudaka7: a atitude política ambivalente frente à pornografia, construindo um deslocamento irônico, autorreflexivo e contra-hegemônico do pornô. "Sin porno, no hay pos-porno", declara Laura Milano (2014:21)

\footnotetext{
7 "Sudaca" é um termo pejorativo cunhado na Europa hispanohablante para se referir aos sul-americanos. No livro "Usina Posporno" (2014), Laura Milano apropria-se da expressão para pensar a pós-pornografia latinoamericana, fazendo um jogo de palavras com a palavra "acá" (em português, aqui), sud-acá. Este mesmo uso pode ser encontrado em textos ainda mais antigos, como os Hija de Perra (2012). Nos últimos anos, tem sido comum entre ativistas a grafia com "k", para marcar no léxico do português e do espanhol do Sul a influência das línguas indígenas e africanas. Para um aprofundamento na discussão, ver Ferreira Gonçales, 2018.
}

Dossiê Feminismos vitais - https://revistaecopos.eco.ufrj.br/

ISSN $2175-8689$ - v. 24, n. 1, 2021

DOI: 10.29146/ecopos.v24i1.27574 
De acordo com Carri, em debates à época do lançamento no Brasil, todas as atrizes são ativistas feministas e encararam o longa-metragem como um projeto político. 0 melhor exemplo é a presença de Rosario Castelli, que interpreta a personagem Rosario, performer da incrível cena final - uma ode à habitual cena de masturbação clitoriana direcionada para a câmera, recorrente no universo pornô desde os stag films da primeira metade do século XX. Rosario é ativista lésbica e feminista, autora do texto "Un posporno situado" (2012), publicado na internet para fins de divulgação da I Muestra de Arte Pospornografico, primeira mostra pós-pornô a acontecer na Argentina. Laura Milano, pesquisadora do tema e autora do livro "Usina posporno: disidencia sexual, arte y autogestión en la pospornografia" (2014), também aparece na longa sequência de festa que finaliza o filme, momento que emula práticas de happenings e performances dos festivais e mostras pós-pornô.

Em As filhas do fogo, fica perceptível a pesquisa intensa e imersiva de Carri na cena pós-pornô argentina, um dos países cuja rede de produção e circulação desse tipo de imagens é das mais fortes (SARMET, 2015). Mas este texto não é uma mera análise deste filme; o longa dirigido por Carri é ponto de partida para pensar as dinâmicas e características político-estéticas das redes pós-pornô da América Latina e como, nelas, a performance e o coletivo são elementos centrais. Não apenas as performances nas obras, mas também o entendimento de que as atuações nas redes sociais e eventos fazem parte de uma performance ativista ampliada que retroalimenta as próprias obras e, nesse sentido, conectando as performances contemporâneas à tradição da arte feminista dos anos 1970.

\section{Centralidade da performance e a tradição da arte feminista}

0 pós-pornô está vinculado a um processo onde arte, modos de produção coletivos, ativismo e uso político dos meios de comunicação se coadunam para trazer visibilidade a modos de vida, sexualidades e corpos dissidentes. Sob tal chancela, o repertório da pornografia é desmantelado para se enfatizar um discurso performático 
sobre os corpos e desejos de mulheres, pessoas queer, não-binárias e trans. As relações entre a arte da performance e feminismo não são inusuais, em especial na América Latina. Conforme reconta Andrea Giunta ${ }^{8}$, a arte feminista latina desde os anos 1970/80 se centra na performance como formas de interrogar as chaves da normalização e disciplinamento do corpo: "Desde os setenta, o corpo importava de maneiras novas. Entraram na cena muitas as formas de senti-lo e conceitualizá-lo" (Giunta, 2019: 14)9 em especial, a performance que implica o corpo da própria artista, trazendo para a obra uma outra camada de atuação política, mesmo quando termos como "feminismo" ou "feminista" não eram oficialmente reivindicados pela crítica e historiografia, ou até pelas próprias artistas.

A presença das mulheres na realização de obras que dialogam com o campo da pornografia acaba por acionar estratégias estéticas e discursivas sobre o domínio do próprio corpo e do próprio prazer. Observando as produções e também as discussões empreendidas por essas mulheres, debate muitas vezes presentes em seus perfis e redes sociais, fica perceptível que as várias agendas feministas se expressam filmicamente de três modos principais: a tradução estética das interações consensuais ou "construção narrativa do consentimento" (Baltar, 2019); o valor de co-participação entre parceires, que sedimenta desejo e prazer como partilha, em contraste à busca pelo prazer individual prevalente na pornografia hegemônica; a exaltação do prazer de mulheres e pessoas trans a partir das noções de empoderamento e de pornificação de $s i^{10}$

Sites, colunas e aplicativos são espaços de consolidação de redes nas mãos das feministas (pós)pornógrafas através da criação de revistas online colaborativas, blogs, zines; do uso de redes sociais como Instagram, Twitter e Tumblr (antes desta proibir

\footnotetext{
8 Andrea Giunta é uma das curadoras da exposição "Mulheres Radicais: arte latino-americana, 19601985" junto com Cecilia Farjado-Hill. A exposição, montada a convite do Hammer Museum, de Los Angeles, foi exibida na Pinacoteca de São Paulo em 2018.

9 "Desde los sesenta el cuerpo importaba de maneras nuevas. Fueron muchas las formas de sentirlo y conceptualizarlo que entraron en escena" (Giunta, 2019: 14)

10 "Pornificação de si" é um conceito de Baltar (2018) que diz respeito à reivindicação do direito e o prazer em se pornificar, fugindo assim da ideia cisheteronormativa de que ser "objeto" do prazer é ser passivo e ser passivo é culturalmente identificado com performatividades de feminilidades.
}

Dossiê Feminismos vitais - https://revistaecopos.eco.ufrj.br/

ISSN 2175-8689 - v. 24, n. 1, 2021

DOI: 10.29146/ecopos.v24i1.27574 
nudez). Todas essas plataformas são mais que lugares de exposição das obras, são lugares de performance de um "eu-ativista", ou seja, as plataformas das redes sociais e a internet são agenciadas pelas pornógrafas e performers como arena de ampliação das ideias políticas que permeiam a criação das obras, intensificando uma interrelação entre criação e ativismo que se traduz em uma atuação cotidiana nestas mesmas redes sociais que a um só tempo expõe e constrói um "eu" (o perfil da rede) que se apresenta como ativista e artista. Tais performances acionam uma rede de discursos e parcerias altamente autoconsciente de seu papel ativista, o que ao mesmo tempo legitima politicamente as obras e se traduz esteticamente nelas.

Dentro do circuito latinoamericano associado à pós-pornografia, a mexicana La Bala Rodriguez é interessante exemplo, especialmente o que ela denomina suas fotoperformances realizadas e apresentadas em posts no seu Tumblr e nas suas colaborações com a revista Hysteria! ${ }^{11}$. Nestas imagens, a pose do corpo em relação ao quadro e câmera consegue expressar seu posicionamento político de celebração de um corpo gordo e pornificado, encarnando a crítica à gordofobia e com diversas referências ao repertório cultural mexicano a exaltação à matriz cultural latinoamericana; e todo o uso que a artista faz do vocabulário do debate queer e feminista, presentes nas legendas e títulos das suas imagens, reitera a autoconsciência de seu lugar artista e ativista.

Não por acaso, a performance (performing art), como expressão e forma de arte, foi o terreno privilegiado para as artistas feministas; pois feminismo e performance compartilham, enquanto regimes estéticos e discursivos, a ideia de que as tensões e os questionamentos se expressam no corpo, no cotidiano e estão implicadas no próprio corpo. (Baltar, 2019:313).

Se o feminismo legou para as teorias de gênero e para os saberes das humanidades a cristalização da máxima de que o "pessoal é político", a performance legou para o regime das artes as implicações (estéticas e políticas) dos imbricamentos entre arte e vida, vida e obra. Há toda uma discussão sobre o conceito de performance que não cabe

11 Hysteria! é uma revista mexicana independente que se dedica a pautas relacionadas a questões de gênero e sexualidade, editada por Ivelin Meza e Liz Misterio (https://hysteria.mx/) (acesso em 18 de junho de 2020)

Dossiê Feminismos vitais - https://revistaecopos.eco.ufrj.br/

ISSN 2175-8689 - v. 24, n. 1, 2021

DOI: 10.29146/ecopos.v24i1.27574 
aqui refazer, mas vale mencionar, como lembra Eleonora Fabião (2008 e 2009), que a performance enquanto gênero do regime das artes implica em corpos como materialidade ou tema, o entrelaçamento e "des-mecanização" de fronteiras entre vida e obra, bem como outras fronteiras como sujeito e objeto, verdadeiro e falso. É desse lugar de des-mecanização geral que as feministas enxergaram nas artes da performance seu modo de expressão privilegiado ${ }^{12}$.

Diana Taylor (2013) argumenta que a performance tem papel fundamental na construção contra-hegemônica de saberes não institucionalizados pelo discurso oficial, o que nos leva a entender esta como uma prática central para o feminismo, posto que reúne pelo menos duas dimensões da teoria feminista: a desnaturalização de comportamentos e práticas cotidianas que construíram os significados do ser mulher e a centralidade do corpo como práxis política.

Observando os perfis e sites das realizadoras/ativistas, bem como suas produções, percebe-se uma rede de menções e autorreferências que, mais que mobilizar o fluxo de colaborações, formam um mapa político das agentes desse campo pós-pornográfico. Estas interconexões são mais que o jogo habitual das estratégias de marketing contemporâneas próprias da vida e consumos midiáticos, são também uma performance expandida que, podemos pensar, ecoa a tradição das relações entre arte feminista e o campo da arte da performance desde os 1970. É através de uma verdadeira gestão ativista das performances de si empreendidas nas redes sociais e na internet que pautas importantes como ética de trabalho, garantia do consentimento e o respeito e exaltação de corpos e prazeres dissidentes são levantadas e onde são apontados exemplos de obras e agentes, tendo como resultado a deflagração de um grande processo multiplicador que consolidam de modo político e estético as redes de cooperação do pós-pornô sudaka.

12 Como exemplos podemos citar obras fundamentais como Rape Scene (1973) e Glass on body imprints (1972), de Ana Mendieta; Tap and Touch Cinema (1968), de VALIE EXPORT; os fotopoemação de para e $o$ que sobre de Anna Maria Maolino (1974); Eat me (Coma-me), de Lygia Pape (1975) e Preparação 1, de Letícia Parente (1975), as peformances de Maris Bustamante e Mónica Mayer, no coletivo Polvo de Gallina Negra (1983).

Dossiê Feminismos vitais - https://revistaecopos.eco.ufrj.br/

ISSN 2175-8689 - v. 24, n. 1, 2021

DOI: 10.29146/ecopos.v24i1.27574 
Julia Bryan-Wilson (2015) defende que para empreender uma história da arte em especial da arte feminista contemporânea - é necessário fazer uso de um modelo metodológico afetivo, ou seja, percorrer um mapa emotivo e pessoal que recubra redes de afeto, amizade e relacionamento ${ }^{13}$. No próximo item, esboçamos uma tentativa de um mapa afetivo da pós-pornografia na América Latina, apontando marcos temporais de sua trajetória baseados na criação e manutenção de uma rede política de produção intelectual, artística e afetiva, gestada sobretudo nas mostras e festivais, seminários, oficinas e na produção coletiva de obras audiovisuais.

\section{Redes pós-pornô latinoamericanas: um mapa afetivo}

As Filhas do Fogo e outras obras audiovisuais que circulam no circuito póspornográfico vinculam-se a um amplo contexto contemporâneo de emergência de uma produção pornográfica dissidente, tributária do feminismo pró-sexo ${ }^{14}$, onde se percebe a presença intensa e politicamente atuante de realizadoras mulheres, pessoas trans, queer, não-binárias, racializadas, gordas, com deficiência, até não muito tempo atrás relegadas ao campo do "fetiche" nos sites de pornografia tradicionais. Hoje, grande parte dessas agentes constrói uma agenda política crescente em torno da ideia de um "pornô ético"15, com pautas consolidadas como a \#PayForYourPorn"16. Essa onda

\footnotetext{
${ }^{13}$ A autora reflete sobre os envolvimentos afetivos do pesquisador, analisando sua própria participação no projeto de criação de mídias alternativas queer Joanie 4 Jackie, criado por Miranda July em 1995. Estamos recuperando as concepções de Bryan-Wilson para ressaltar como as mesmas redes afetivas estruturam parcerias e fluxos de cooperação política que se refletem diretamente na estética nas redes pós-pornôs da América Latina.

${ }_{14}$ Em resposta ao alinhamento de parte do movimento feminista estadunidense à agenda de grupos conservadores, Ellen Willis publica em 1981 o artigo "Lust Horizons: Is the Women's Movement ProSex?", no qual faz duras críticas ao feminismo anti-pornografia pelas alianças com a direita e organizações religiosas em prol da luta contra a pornografia e a prostituição. Nasce aí o termo "feminismo pró-sexo", que vai mobilizar acadêmicas feministas como Gayle Rubin, Pat Califia e Carol Queen. As feministas prósexo criticavam o movimento anti-pornografia por defender o que elas viam como formas de opressão da sexualidade em favor da censura.

${ }^{15}$ Para um aprofundamento da expressão e do movimento em torno dela, ver https://ethical.porn.

${ }^{16}$ A hashtag \#PayForYourPorn tem a intenção de conscientizar os consumidores de pornografia online sobre os modos de produção de sites de streaming "gratuito", como Xvideos, PornHub, YouPorn, RedTube, os três últimos todos pertencentes à canadense MindGeek, maior conglomerado de pornografia online do mundo. 0 conteúdo desses sites tipo "tube" muitas vezes é pirateado de produtoras menores, conteúdo
}

Dossiê Feminismos vitais - https://revistaecopos.eco.ufrj.br/

ISSN 2175-8689 - v. 24, n. 1, 2021

DOI: 10.29146/ecopos.v24i1.27574 
feminista que reivindica termos como ética e queer (com isso reiterando o alinhamento a uma agenda política que apregoa a importância da consensualidade, respeito, sobretudo do ponto de vista trabalhista, entre outros pontos) tem adentrado até mesmo a indústria mainstream, que em 2020 foi inundada pela hashtag \#PornStrike, uma espécie de \#MeToo da pornografia estadunidense ${ }^{18}$, que tem sofrido intensas modificações e deslocamentos em razão da ampliação das possibilidades dos conteúdos serem produzidos de modo independente pelas próprias performers.

A produção pornográfica menos vinculada ao circuito comercial e de mercado circula sob a chancela do termo pós-pornô ou pós-pornografia, que além de demarcar certas recorrências estéticas e de repertório, demarca um circuito específico onde arte, mídia, ativismo e performance se encontram no e com o domínio do pornográfico.

0 termo "pós-pornô" foi recuperado e atualizado em um contexto de politização da pornografia por ativistas e teóricos europeus a partir dos anos 2000. Desde então, o termo é amplamente usado para designar performances e obras explicitamente ativistas que colocam em tensionamento os preceitos associados à pornografia comercial, amparado na chancela oferecida por intelectuais da teoria de gênero e queer como Sam Bourcier (2005) e Paul B. Preciado ${ }^{19}$ (2007, 2008, 2010).

pago produzido pelas próprias performers e disponibilizado gratuitamente, sem nenhum tipo de remuneração às produtoras das imagens.

${ }^{18}$ Diferentemente de outros momentos em que a indústria pornográfica estadunidense, principalmente, foi tomada por denúncias de violências sexuais, na hashtag \#PornStrike promovida em 2020 no Twitter as denúncias de estupros e abusos em grandes estúdios vieram acompanhadas de intensa discussão e compartilhamento de estratégias para que as performers se tornassem produtoras de conteúdos independentes, gesto fomentado pela paralisação de gravações em razão da pandemia da Covid-19. Uma grande influência para essa tomada feminista parece ter sido a efervescência dos protestos contra o assassinato de George Floyd e as discussões em torno do movimento Black Lives Matter, que levou performers negras, não-brancas e brancas a se posicionarem sobre o racismo em seus perfis pessoais, pressionando os estúdios por medidas de combate ao racismo na pornografia. Como estamos argumentando ao longo deste artigo, é fundamental entender tais movimentações nas redes sociais como uma extensão das performances, desdobrando as relações estético-políticas para outras esferas para além do "texto" das obras.

${ }^{19}$ Preciado pode ser considerado a principal referência teórica dessa nova "era" pós-pornográfica, tendo sido responsável pela organização da "Maratón Posporno", projeto de formação ocorrido no Museu de Arte Contemporânea de Barcelona em 2003, de onde se originaram vários coletivos e artistas autônomos que viriam a formar a rede pós-pornô catalã, como Post Op, Quimera Rosa, Go Fist Foundation, dentre outros.

Dossiê Feminismos vitais - https://revistaecopos.eco.ufrj.br/

ISSN 2175-8689 - v. 24, n. 1, 2021

DOI: 10.29146/ecopos.v24i1.27574 
A ativista pelos direitos das trabalhadoras sexuais, performer, artista, diretora de filmes pornográficos e sexóloga Annie Sprinkle é largamente reconhecida como a responsável pela popularização do movimento pós-pornográfico, ao ponto de por vezes ser identificada como a "mãe" do pós-pornô. Menos conhecido do que Sprinkle é o contexto em que o termo passou a ser empregado por ela para designar seu trabalho. Em 1983, em Nova Iorque, Sprinkle, juntamente a Veronica Vera, Gloria Leonard, Kelly Nichols, Sue Nero, Veronica Hart e Candida Royalle, todas atrizes e/ou diretoras de filmes pornôs fundam o Club 90, grupo de encontros e rede de apoio entre mulheres para discutir questões relativas ao trabalho sexual, ao feminismo e às suas vidas pessoais. Dentre as discussões do grupo estava, por exemplo, o fato de o mercado pornográfico à época não reconhecer o sexo lésbico como sexo e, assim, não pagava às atrizes pelas cenas do tipo (Bell, 1994: 144). Desses encontros resultaria a performance Deep Inside Porn Stars ${ }^{20}$ (1984), um interstício entre teatro e vida pessoal baseado nas discussões do Club 90. A performance tinha por premissa mostrar como atuar na indústria pornográfica podia ser "prejudicial" e "libertador" ao mesmo tempo (ibid.: 145). Apesar da marginalização à qual usualmente são relegadas as trabalhadoras sexuais, essas mulheres também eram artistas que frequentavam ativamente espaços das artes visuais e de performance, desenvolvendo trabalhos e exposições sobre suas vivências; também participavam ostensivamente da militância feminista, marcando um posicionamento de defesa das trabalhadoras sexuais que tensionava o feminismo antipornografia vigente na época. Dessa forma, iniciaram um intercâmbio cultural e político entre indústria pornográfica, arte e militância feminista que caracterizaria um modo próprio de vida e ativismo e resultaria no Movimento Pós Pornô Modernista.

De acordo com Spinkle (Stüttgen, 2009: 102), o termo teria sido tomado emprestado do fotógrafo holandês Wink van Kempen ${ }^{21}$ para o título de seu espetáculo

200 título faz alusão a um dos chavões do jornalismo de culto às celebridades, lógica que já estava presente no universo pornô nos anos 80. Também se refere a um filme dirigido por Sprinkle um ano antes. Em 1982, Sprinkle seria uma das primeiras mulheres a dirigir um longa-metragem de sexo explícito, no qual também atua, Deep Inside Annie Sprinkle (SPRINKE, 1982).

${ }^{21}$ Em entrevista a Sttugen (2009), Sprinkle afirma ter criado o título de sua performance inspirada em exposição fotográfica homônima de Kempen, que passou a ser reconhecido como a origem do conceito, embora em realidade sua exposição, exibida em Rotterdam em 1986, fosse intitulada "Porn Modernism".

\section{Dossiê Feminismos vitais - https://revistaecopos.eco.ufrj.br/}


solo Post Porn Modernist, lançado em 1990 e constituído por um apanhado de performances que a artista vinha fazendo em Nova Iorque desde 1984. Entretanto, segundo Bell (1994), a expressão aparece em 1989 no Manifesto Pós Pornô Modernista²2, escrito pela atriz pornô, escritora e integrante do Club 90 Veronica Vera. 0 manifesto foi assinado por atrizes e diretoras da indústria pornográfica, bem como artistas visuais e performers cujos trabalhos eram atravessados pelos temas do sexo e da sexualidade. Mais adiante, com a popularização do conceito por Spinkle, a palavra "modernista" seria abandonada, mas naquele momento atuava como um termo estratégico para a negociação do pós-pornô dentro do mundo institucional da Arte. Assim, a póspornografia nasce como um movimento híbrido, resultante do diálogo entre a indústria pornográfica, a arte e a política, em um momento histórico no qual intensos debates estavam sendo travados no interior do feminismo e na esfera pública sobre o papel da pornografia, sua representação dos corpos das mulheres e os direitos das trabalhadoras sexuais.

O pós-pornô não busca censurar ou acabar com a pornografia hegemônica, mas sim problematizar e tensionar o pornô como lugar privilegiado de produção de sentido sobre o corpo, a sexualidade e o desejo. Assim, a desnaturalização do imaginário pornográfico e sexual empreendida pela pós-pornografia não se dá em oposição à pornografia comercial tradicional, mas sim por meio de um diálogo crítico que se

A expressão "pós-pornografia" (post-pornography), a rigor, foi primeiramente empregada por Walter Kendrick em 1986, em seu livro "The Secret Museum - Pornography in the Modern Culture". Kendrick sugeriu o termo alinhando o momento da pornografia com os pensamentos sobre pós-modernidade em voga nos anos 1980, possivelmente a mesma motivação de Sprinkle e Vera.

220 Movimento Pós Pornô é fundado em um momento estratégico, quando políticos conservadores dos Estados Unidos buscavam censurar exposições e artistas que trabalhavam com temas ligados à sexualidade no país. Em 1989 o pastor Donald Wildmon, representando a conservadora American Family Association iniciou uma batalha contra o financiamento estatal de obras de arte que ele julgava defenderem "preconceitos anticristãos". A partir das denúncias de Wildmon, dois senadores republicanos começaram a mobilizar forças contra o NEA (National Endowment for the Arts), órgão federal dedicado a apoiar e financiar obras de excelência artística. Diversos artistas visuais e performáticos sofreram sistemáticos ataques da imprensa e do congresso devido ao conteúdo "imoral" ou "obsceno" de suas obras. Pouco menos de um mês após a polêmica envolvendo Wildmon, a revolta de alguns congressistas com o conteúdo homoerótico e sadomasoquista das obras do fotógrafo Robert Mapplethorpe levou ao cancelamento de sua exposição "The Perfect Moment" em uma famosa galeria de arte em Washington. Para mais informações, ver Quigley, "The Mapplethorpe Censorship Controversy", disponível em http://www.publiceye.org/theocrat/Mapplethorpe Chrono.html. Acesso em 04 de julho de 2021.

Dossiê Feminismos vitais - https://revistaecopos.eco.ufrj.br/

ISSN 2175-8689 - v. 24, n. 1, 2021

DOI: 10.29146/ecopos.v24i1.27574 
estabelece através da negociação com seus códigos hegemônicos, criando algo híbrido que é por isso mesmo disruptivo em sua própria ordem. Entre suas estratégias estéticas e narrativas, podemos elencar: a representação de corpos e praticas sexuais historicamente marginalizados ou fetichizados pela pornografia mainstream; a alusão e a subversão de certos códigos narrativos clássicos da pornografia comercial tradicional, como os close-ups no pênis e no Money shot ${ }^{23}$, o binômio passividade (feminina) x atividade (masculina), o hiperestímulo pela hipervisualidade e manipulação do som; a recorrência de um excesso visual que remete às tradições do artificio, da body art, da cultura BDSM, do teatro burlesco e do cinema de atrações, dentre outras.

Os aspectos específicos da pós-pornografia na América Latina foram densamente analisados e pormenorizados na dissertação de Érica Sarmet (2015), e cabe aqui recuperar, de modo breve, as principais estratégias estéticas elencadas pela autora. Assim, é importante apontar, para a pós-pornografia latina: o excesso como estratégia de rescrita de uma história política; o questionamento das divisões binárias de gênero a partir de uma estética do grotesco que trabalha a ambivalência do corpo; o diálogo explícito com a pornografia tradicional, reenquadrada a partir de uma retórica da intimidade e do afeto; a recuperação e atualização da tradição da blasfêmia como estratégia política e estética de questionamento da moral sexual cristã e da violência colonial. Assim como em outros movimentos artísticos-intelectuais do Sul Global, a póspornografia latinoamericana reinscreve o presente e o passado, renovando-os simultaneamente na produção de um movimento artístico-político que carrega em discurso e forma sua ambivalência, seu excesso e seu caráter fronteiriço, transcultural e coletivo.

Tomado da cultura punk anticapitalista, o conceito de D.I.Y (Do It Yourself, "Faça Você Mesmo") é uma das premissas que sustentam a produção e circulação de imagens pós-pornográficas. Contudo, como aponta Milano (2014), na pós-pornografia a lógica

${ }^{23}$ Cumshot ou Money shot é a expressão vigente no mercado pornográfico para designar o plano close-up da ejaculação do pênis, que precisa ser necessariamente fora do corpo do parceiro de cena para a ejaculação seja visível para o espectador. Devido ao seu papel de atestar veracidade ao sexo representado na tela, o Money shot é considerado pelos produtores de filmes pornográficos o plano mais caro desse tipo de produção.

Dossiê Feminismos vitais - https://revistaecopos.eco.ufrj.br/

ISSN 2175-8689 - v. 24, n. 1, 2021

DOI: 10.29146/ecopos.v24i1.27574 
"Faça Você Mesmo" transforma-se em um "Faça Com Outros". Muitos são os filmes, festivais, performances, manifestos e intervenções urbanas gestados coletivamente. Tal trabalho colaborativo possibilitou a criação na América Latina de um circuito alternativo próprio no qual essas produções pudessem circular à revelia dos mercados de arte, cinema e pornografia. As redes pós-pornô se organizam e se retroalimentam a partir de ações intermidiais - filmes, videoartes, performances, poesias, fotografias, manifestos, prosas, ensaios e artigos acadêmicos - que, por sua vez, são articuladas em encontros presenciais como mostras, festivais, seminários e oficinas. Em muitos casos, esses encontros resultaram na formação de coletivos e no estreitamento de laços afetivos entre artistas e ativistas de diversos territórios, intensificados pela difusão online da produção intelectual e artística elaborada sobre ou nesses contextos.

No âmbito de espaços de exibição e circulação, temos o ano de 2011 como um detonador criativo. Em Bogotá, Colômbia e Buenos Aires, Argentina, foi realizado em julho o Festival Porno Porsi. Porno PorSi 24 foi um coletivo criado em 2009 que organizou os festivais Porno PorSi, encontros itinerantes onde produções pornográficas em múltiplos formatos foram planejadas, produzidas e exibidas. Após 2011, as ações do coletivo enquanto tal cessaram, mas os grupos criados em torno dos festivais seguiram atuantes, sobretudo os argentinos Cuerpo Puerco e Acento Frenético.

Alguns meses antes, no Brasil, Suzy Capó lança o PopPorn, inspirado no Pornfilmfestival Berlin. Ainda que sem articulações com as redes gestadas naquele momento em Argentina, Colômbia e Chile, sua criação parte de um desejo compartilhado de articular outros imaginários sexuais, distintos da pornografia comercial mainstream. A crítica à moral sexual cristã é outro pilar, tributário de extensa e antiga tradição na arte queer e feminista latinoamericana de conjugar religião e sexualidade como estratégia de confronto e deboche da violência colonial da catequização ${ }^{25}$. Em texto escrito à época, Capó coloca o festival como "fundamental em um momento de expansão do fundamentalismo religioso no Brasil, um manifesto contra

${ }^{24}$ Para mais informações, ver https://proyectopornoporsi.wordpress.com.

25 Para um aprofundamento na blasfêmia como estratégia política e estética de questionamento da moral sexual cristã na história da arte latinoamericana e sua reatualização pelo pós-pornô contemporâneo, conferir o Capítulo 3 de Sarmet (2015).

Dossiê Feminismos vitais - https://revistaecopos.eco.ufrj.br/

ISSN 2175-8689 - v. 24, n. 1, 2021

DOI: 10.29146/ecopos.v24i1.27574 
a intervenção de igrejas no Estado secular, um antídoto contra o conservadorismo que inibe a expressão livre da sexualidade"26. No Brasil, no mesmo ano, acontece também o Composições Políticas (2011), projeto da Associação Cultural Panorama no Rio de Janeiro que contou com uma oficina sobre pós-pornografia de Maria Llopis, artista e ativista espanhola, e uma apresentação de Congelada de Uva, performer mexicana.

Em Santiago do Chile, um mês após o Porno PorSi (2011) acontece o I Festival Festival de Video Arte Porno Dildo Roza ${ }^{27}$ (2011). Para além do festival, o projeto foi pensado de maneira expandida por Sebastian Echevarría como uma galeria de arte virtual para projetos que convergem arte e sexo e a galeria enquanto obra, tese defendida na graduação da Universidad de Chile ${ }^{28}$. Entre os artistas vinculados ao projeto estava Hija de Perra, apresentadora do festival e figura emblemática do ativismo sexodissidente, transfeminista, monstruoso e marginal chileno, falecida em 2014. Na equipe de curadoria constava entre outros nomes a CUDS (Coordenação Universitária pela Dissidência Sexual) ${ }^{29}$, coletivo formado em 2002 após uma cisão no Comitê de Esquerda pela Diversidade Sexual, vinculado ao Partido Comunista chileno. Em 2009, influenciados pela vinda de Preciado ao Chile $^{30}$ alguns anos antes e a circulação de textos de teóricos queer, criaram um coletivo interno de produção pós-pornográfica, o Subporno. Composto em sua maioria por estudantes de cinema, o Subporno era cogestor do projeto "Laboratório de Porno-resistência", oficinas organizadas pela CUDS e

\footnotetext{
${ }^{26}$ Ver mais em: https://www.popporn.com.br/wp-content/uploads/pp10history.pdf. Acesso em 15 de junho de 2020.

${ }^{27}$ Para mais informações, ver https://www.mabuse.cl/festivales.php?id=86519.

${ }^{28}$ http://repositorio.uchile.cl/handle/2250/114542. Acesso em 15 de junho de 2020.

${ }^{29} \mathrm{O}$ artista visual e pesquisador chileno Felipe Rivas San Martín, um dos fundadores da CUDS e diretor do vídeo Ideologia (2011) trabalha com o conceito de "dissidência sexual" para nomear as práticas e discursos vinculados ao queer na América Latina. Crítico à noção de uma identidade queer, segundo o artista a CUDS só começou a trabalhar com o conceito de dissidência sexual em 2005. Antes disso, a letra "D" representava "diversidade", mas esta se mostrava uma palavra cada vez mais assimilada pelo discurso capitalista hegemônico e que não suscitava o questionamento da fixidez das identidades sexuais. "(...) nosotros hablamos de disidencia sexual, porque era la manera de dejar de lado las identidades de manera radical. Porque disidencia sexual no te dice cuál es tu identidad, sino cuál es tu posicionamiento político. Lo que importa para la disidencia es tener un posicionamiento crítico con respecto a un marco de normas culturales, sexuales" (Rivas San Martín em entrevista ao site Arte y Crítica, 2012).

30 Para um aprofundamento na discussão sobre os tensionamentos entre a produção intelectual/artística latinoamericana vinculada às questões de gênero e sexualidade e os estudos queer estadunidenses e europeus, ver Sarmet (2015).
}

Dossiê Feminismos vitais - https://revistaecopos.eco.ufrj.br/

ISSN 2175-8689 - v. 24, n. 1, 2021

DOI: 10.29146/ecopos.v24i1.27574 
pela revista Disidencia Sexual. Suas produções envolviam desde o registro de manifestações políticas à produção de filmes, performances e oficinas, entre as quais o curta-metragem Esto es Chile (2010), no qual uma performer se masturba com um dildo - cor de rosa - no formato geográfico do país.

Esse gesto de fazer referência a uma produção local próxima corrobora nosso argumento acerca da importância de uma retroalimentação dessas redes pós-pornô a partir de um jogo de autorreferências. Utilizando-se da esfera midiática e da penetração de certos agentes em ambientes acadêmicos e artísticos estratégicos, esses coletivos, grupos e sujeitos moldaram uma espiral de compartilhamento e autocitação uns dos outros que contribuiu intensamente para a formação, de fato, de uma rede transnacional e transterritorial pós-pornográfica, conectada e sustentada por essas relações.

Nos anos seguintes, esse processo foi sedimentado e intensificado com a realização do NO.POR.NO - 1ํㅗ Simposio sobre pospornografía y cultura visual, em março de 2012, na Facultad de Bellas Artes, Universidad Autónoma de Querétaro, México; a 1aㅗ Bienal de Arte e Sexo, em Santiago do Chile, em novembro de 2012; também em 2012, ocorreram a I Muestra de Arte Pospornografico de Buenos Aires, Argentina, e o Festival Sexuantes: (post) pornô, cuerpo, poder y arte, em Lima, Peru. No Peru, esse movimento foi catalisado principalmente pela figura de Héctor Acuña/Frau Diamanda, também responsável pelo Pornífero Festival, que começou em Lima em 2014 e já teve edições em Bogotá (2015) e Barcelona (2017), onde foram exibidos trabalhos da performer anarcatransfeminista Bruna Kury, integrante dos coletivos pornoterroristas e anti-arte Coiote e Vômito, e ela própria organizadora do festival de cultura e política sexodissidente KUCETA (póspornografias), ocorrido em São Paulo em junho de 2018. Esses são apenas alguns, dentre dezenas de mostras e festivais articulados nos últimos anos, com intensa troca internacional entre organizadores e performers.

Em tais eventos, estão presentes debates que circundam questões de gênero, sexualidade, sexo, raça, etnia, arte e política, mas em especial discussões em torno dos marcadores das diferenças latinoamericanas no que diz respeito às epistemologias 
queer e feminista estadounidenses e européias. Desse modo, a pós-pornografia latinoamericana fundamenta-se em uma relação ambivalente e constantemente tensionada e negociada entre produção e teorização local e os referenciais de saberes e criações artísticas "gringos". Entre os diversos campos de disputa, está a historicização das práticas artísticas latinoamericanas sexodissidentes.

Ao longo da história da arte latinoamericana, inúmeros artistas trabalharam com questões referentes a corpos, sexualidades, gêneros e pornografia sem que suas obras fossem nomeadas de queer, pós-pornô ou até feministas. Para a filósofa chilena Alejandra Castillo (2012), a ausência de uma genealogia das práticas artísticas latinoamericanas vinculadas ao corpo, principalmente no que diz respeito à arte feminista, fez com que o pós-pornô tenha sido recebido nos territórios latinoamericanos com ares de novidade, uma espécie de "modernização espanhola" quando, na verdade, as artistas latinas há muito já levantavam questionamentos semelhantes, notadamente desde os anos 1980 e até mesmo antes (Sarmet, 2015).

É crucial retomar esses exemplos para reafirmar como as relações entre o questionamento estético-político dos valores eurocêntricos, brancos e heterocisnormativos estão historicamente agarrados às práticas que vão das performances nas obras às performances cotidianas das artistas.

Entre exemplos mais notórios, temos: o Movimento de Arte Pornô (1980-1982) ${ }^{31}$ no Brasil, o chileno Las Yeguas del Apocalipsis (1987-1993), de Pedro Lemebel e Francisco Casas e as performances experimentais do Grupo Chaclacayo (1983-1994) no Peru. Mas a lista é extensa e nela cabem ainda as obras de Márcia X, as performances drag queen de Laura de Vision, as reapropriações queer das cabareteras mexicanas, a tradição da arte feminista chicana de ressexualizar a imagem da Virgem de Guadalupe, todas obras e ações cujas estratégias estéticas são calcadas no excesso, empregado com o intuito de tensionar através do corpo e da sexualidade os traços formadores de uma

31 Para um apanhado mais completo sobre a história do Movimento de Arte Pornô, ver KAC, 2013.

Dossiê Feminismos vitais - https://revistaecopos.eco.ufrj.br/

ISSN 2175-8689 - v. 24, n. 1, 2021

DOI: 10.29146/ecopos.v24i1.27574 
suposta identidade latinoamericana pautada no estereótipo da passionalidade, no sentimentalismo e na sensualidade ${ }^{32}$.

0 que a pós-pornografia latinoamericana recupera diretamente desta genealogia mencionada acima são a aproximação às formas de espetáculo circense; a alusão à estética kitsch da novela sentimental; a violência verbal e simbólica direcionada à colonialidade e à hegemonia (sobretudo nos manifestos produzidos); a tendência à hipérbole, ao exagero e ao espetáculo (traços em si de uma estética do excesso); a inversão dos códigos estéticos e sociais preestabelecidos e diversas formas de expressão do humor, como a paródia, o grotesco, o deboche e a ironia.

Além do Coletivo Coiote e Bruna Kury, já mencionados, na produção contemporânea destacam-se nomes como Nadia Granado/La Fulminante (Colômbia), Ayli Habibi (Colômbia/Argentina), Taís Lobo (Brasil), Lucía Egaña Rojas (chilena radicada na Europa ${ }^{33}$ ), Congelada de Uva (México), Lechedevirgen Trimegisto (México), Érika Ordosgoitti (Venezuela), PornoClown (Brasil), La Bala Rodríguez (México), Kono la cerda punk (Chile), Felipe Rivas San Martín (Chile), o coletivo Terrorismo Teatral Migrante (Chile), Acento Frenético (Argentina), Cuerpo Puerco (Argentina), e, mais recentemente, Virar Films (Argentina). Alguns desses coletivos não existem mais, outros foram se desdobrando em novas ações e projetos, tecendo novas relações e deslocamentos que seguem ampliando e expandindo as redes pós-pornôs dos territórios daqui, formadas há pouco mais de dez anos.

32 Há todo um debate sobre o conceito de América Latina e as matrizes culturais desse território (entendendo território como espaço geopolítico e cultural cujos limites e fronteiras estão em constante disputa). Nesse debate é importante lembrar que América Latina é uma invenção colonial, mas que por outro lado, em diversos momentos da história cultural mais recente foi reivindicado como arena política coletiva de uma historicidade comum pautada na experiência colonial e neocolonial (como fica explícito nos manifestos e debates em torno do Tercer Cine, do Cine Imperfecto dos anos 1960, por exemplo). As redes pós-pornô delineadas aqui neste artigo com frequência reivindicam o vocabulário de latina/latinidade e com ele reafirmam a circulação de ideias, agentes e obras, travando um diálogo, nas obras e nas discussões sobre elas, com uma história da arte política que também reivindicaram a latinidade. Podemos perceber esse diálogo e reivindicação de uma latinidade por exemplo, nas performances de La Fulminante (http://lafulminante.com/), no projeto Porno PorSi ou mesmo nas contribuições da revista Hysteria.

33 Diretora do documentário "Mi sexualidad es una creación artística" (2011), sobre a cena pós-pornô de Barcelona, e fundadora do Instituto de Estudios del Porno: http://institutodelporno.net/

Dossiê Feminismos vitais - https://revistaecopos.eco.ufrj.br/

ISSN 2175-8689 - v. 24, n. 1, 2021

DOI: 10.29146/ecopos.v24i1.27574 
Dentre as transformações mais visíveis da pós-pornografia na última década está o uso estratégico da internet e das redes sociais para além da divulgação dos encontros e ações dos coletivos ou da circulação das obras, como ferramenta de ativismo político. Nas redes, imagens sensíveis comuns vão sendo consolidadas e um léxico demarcador vem se perpetuando: termos como kuir, cuir, sudakas, gordentes, teoria $\mathrm{cu}^{34}$, caravela queer $^{35}$, cis-tema, desculonizacíon. Os conceitos vão ficando conhecidos e reconhecidos através das obras e das performances na vida online, e cada vez mais artistas vêm sendo referências bibliográficas nesse regime de autocolaboração e citação, mais um aspecto da articulação em rede defendida neste artigo.

Talvez a imagem que melhor sintetiza o mapa afetivo-performativo-político da pós-pornografia latinoamericana seja o perfil de Instagram da performer Bruna Kury (@bruna_kury). Na rede social, a artista aciona poses que remetem a suas próprias performances para divulgar, entre outros trabalhos, o projeto PORNOPIRATA discussões e performances em torno de raça, classe, gênero e sexualidade (@po.rnopirata), onde agencia toda uma circulação "pirata" das principais obras póspornô da América Latina. 0 projeto, criado como opção para gerar renda na marginalidade e com o objetivo de popularizar o pós-pornô, remete de modo debochado ao circuito camelô de DVDs piratas que marcam o consumo popular de cinema nas capitais latinoamericanas. Na lista das obras, encontramos todos os nomes mencionados aqui. Através da venda e divulgação desses DVDs, Kury contamina as redes, as galerias e museus de arte e as ruas com conceitos que norteiam essa produção e tomam de assalto esse mapa afetivo-performático-político, como "sexorcismos", "pornoterrorismo", "sexualidades dissidentes", trazendo também uma perspectiva crítica-política que tensiona a predominância de corpos brancos, cisgêneros e de classe média/alta na produção pós-pornô reconhecida como latinoamericana ${ }^{36}$. Em suas palavras, "corpes gordes, travestis, ditas doentes, doentes, cyborgs, kuirs, sudakas, negres, indigenes,

${ }^{34}$ Termo cunhado pela teórica Larissa Pelúcio. Ver Pelúcio, 2014.

35 Termo cunhado pela teórica e artista Jota Mombaça. Ver Mombaça, 2016.

${ }^{36}$ Para um aprofundamento nos debates que tensionam a teoria queer e seus trânsitos em América Latina e África desde uma perspectiva interseccional e racialiazada, ver Rea e Amancio, 2018; sobre essa discussão no campo da arte no Brasil, ver Batista Ferreira, 2016; sobre raça e pornografia mainstream no Brasil, ver Carvalho, 2018.

Dossiê Feminismos vitais - https://revistaecopos.eco.ufrj.br/

ISSN 2175-8689 - v. 24, n. 1, 2021

DOI: 10.29146/ecopos.v24i1.27574 
trans, intersexos, com diversidades funcionais, ditas sujas, sujas, antiheterokapital" (Kury, 2017) 37.

As redes inventariadas aqui - uma inventariação evidentemente panorâmica e necessariamente incompleta - criam mais que novas rotas de realização, de espectatorialidade e de léxico, refundam e reinstauram o papel central da performance como estratégia ativista, em especial para a reflexão política feminista e queer, justamente pelo caráter estético e cotidiano que o performático engendra, consolidando a circulação estético-político entre vida, arte e mídia.

\section{Referências bibliográficas}

ANZALDÚA, Gloria. Borderlands: the new mestiza = La Frontera. 2a edição. São Francisco: Aunt Lute Books, 1999.

BHABHA, H. O local da cultura. Belo Horizonte: Editora UFMG, 1998.

BALTAR, Mariana (org). E pornô, tem pornô? A Panorama of Brazilian Porn. Milão, Mimesis Internacional, 2018.

De mulher para mulher: o campo do pornográfico para deleite dos femininos. In HOLANDA, Karla. Mulheres de cinema. Rio de Janeiro, Numa Editora, 2019.

Corpos, pornificações e prazeres partilhados. In. Imagofagia - Revista de la Asociación Argentina de Estudios de Cine y Audiovisual, n. 18, pag. 564 - 588, 2018.

BALTAR, Mariana.; SARMET, Érica. La fulminante: deboche, excesso e gênero no pós-pornô da América Latina. In. ArtCultura. v.17, p.109 - 124, 2016.

BATISTA FERREIRA, Glauco. 'Arte Queer' no Brasil? Relações raciais e não-binarismos de gênero e sexualidades em expressões artísticas em contextos sociais brasileiros. Urdimento, v. 2, n. 27, p. 206-227, 2016. Disponível em: https://doi.org/10.5965/1414573102272016206

BELL, Shannon. Reading, writing, and rewriting the prostitute body. Bloomington and Indianapolis: Indiana University Press, 1994.

BOURCIER, Marie-Hélène/Sam. Post-pornographie. In: DI FOLCO, Philippe. Dictionnaire de la pornographie, Paris, Presses Universitaires de France, 2005, p. 378-380.

BRAGANÇA, Mauricio. Sexo e raça na virgem mestiça - Imagens guadalupanas e feminismo chicano. Caligrama, v. 2, n. 2, p. 1-11, 2006.

${ }^{37}$ Retirado de https://brunakury.weebly.com/pornopirata.html. Acesso em 15 de junho de 2020.

Dossiê Feminismos vitais - https://revistaecopos.eco.ufrj.br/

ISSN 2175-8689 - v. 24, n. 1, 2021

DOI: 10.29146/ecopos.v24i1.27574 
Corpo, imagem e registro colonial no Corazón Sangrante de Astrid Hadad. Revista Estudos Feministas, v. 19, n. 2, p. 403-419, 201

BRYAN-WILSON, Julia. Envolvida. História da arte feminista e passados afetivos. In. Caderno Sesc_Videobrasil, 11. Alianças de corpos vulneráveis: feminismos, ativismo bicha e cultura visual. Curadoria Miguel A. López. São Paulo, Edições Sesc, 2015.

CARVALHO, Michel. Bombom: esse escuro objeto do desejo. In: RANGEL, Everton, FERNANDES, Camila e LIMA, Fátima (org.). (Des)Prazer da norma. Rio de Janeiro: Papéis Selvagens, 2018.

CASTILLO, Alejandra. "Anestesias de lo visual": hacia un cortocircuito de la representación de lo femenino. Entrevista para Arte y Crítica, 2012. Disponível em http://www.arteycritica.org/entrevistas/anestesias-de-lo-visual-hacia-un-cortocircuitode-la- representacion-de-lo-femenino-conversacion-con-alejandra-castillo/

CAVALERO, Lucía; CASTELLI, Rosario. Un posporno situado. 2012. Disponível em http://muestraposporno.wordpress.com/

DEL RIO, Elena. Powers of affection: Deleuze and the cinemas of performance. Edimburgo: Edinburgh University Press, 2008

FABIÃO, Eleonora. Performance e teatro: poéticas e políticas da cena contemporânea. In. Sala Preta, v. 8, p. 235-246, 28 nov. 2008. DOI:https://doi.org/10.11606/issn.22383867.v8i0p235-246.

Definir performance é um falso problema. Entrevista concedida a Fábio Freire [09 de julho, 2009]. Disponível em: <http://diariodonordeste.verdesmares.com.br/cadernos/caderno-3/definirperformance-e-um-falso-problema-1.281367> Acesso em 05 de Junho de 2020.

FERREIRA GONÇALES, Nathalia. Das ruínas do corpo sudaca: marcas de vulnerabilidade em performances artísticas. In: RANGEL, Everton, FERNANDES, Camila e LIMA, Fátima (org.). (Des)Prazer da norma. Rio de Janeiro: Papéis Selvagens, 2018.

GIUNTA, Andrea. Feminismo y arte latinoamericano. Historias de artistas que emanciparon el cuerpo. Buenos Aires, Siglo Veintiuno editores, 2019.

KAC, Eduardo. O Movimento de Arte Pornô: a Aventura de uma Vanguarda nos Anos 80. ARS, v. 11, n. 22 , p. $30-51,2013$

KENDRICK, W. The Secret Museum: Pornography in Modern Culture. University of California Press, 1987.

KURY, Bruna. Pós-porno e afronta à heteronormatividade compulsória, 2017. Disponível em https://www.tropicuir.org/pos-pornografia-pirata/. Acesso em 15 de junho de 2020.

LÓPEZ, M. A. Queer Corpses: Grupo Chaclacayo and the Image of Death. e-flux, v. 44, p. 01-12, abril de 2013.

Dossiê Feminismos vitais - https://revistaecopos.eco.ufrj.br/

ISSN 2175-8689 - v. 24, n. 1, 2021

DOI: 10.29146/ecopos.v24i1.27574 
MOMBAÇA, Jota. Para desaprender o queer dos trópicos: desmontando a caravela queer. Ssexbbox, ago 28, 2016. Disponível em https://medium.com/@monstraerrtika/paradesaprender-o-queer-dos-tr\%C3\%B3picos-desmontando-a-caravela-queer6ced98495821. Acesso em 06 de junho de 2020.

MILANO, Laura. Usina Posporno: disidencia sexual, arte y autogestión en la pospornografia. 1a ed. ed.Ciudad Autónoma de Buenos Aires: Título, 2014.

PAASONEN, Susanna. Carnal Resonance - Affect and Online Pornography. 1a. ed. MIT Press, 2011.

PELÚCIO, Larissa. Traduções e torções ou o que se quer dizer quando dizemos queer no Brasil. Periodicus, vol. 1, no 1, Salvador, 2014.

PRECIADO, Paul B. Después del feminismo. Mujeres en los márgenes. 2007. Publicado em: http://elpais.com/diario/2007/01/13/babelia/1168648750_850215.html. Pharmaco pornographic Politics: Towards a New Gender Ecology. Parallax, v. 14, n. 1, p. 105-117, 2008. . POSPORNO - Excitación disidente. Parole de Queer, 2010.

REA, Caterina Alessandra e AMANCIO, Izzie Madalena Santos. Descolonizar a sexualidade: Teoria Queer of Colour e trânsitos para o Sul. Cadernos Pagu [online]. 2018, n. 53 [Acessado 20 de Junho de 2020], e185315. Disponível em: <https://doi.org/10.1590/18094449201800530015>. Epub 04 Out 2018. ISSN 18094449. https://doi.org/10.1590/18094449201800530015.

RIVAS SAN MARTIN, Felipe. "Diga 'queer' con la lengua afuera: sobre las confusiones del debate latinoamericano", In. Por un Feminismo sin Mujeres, organizado por CUDS - Coordinadora Universitaria por la Diferencia Sexual. pp. 59---75. Santiago de Chile, 2011.

SABO, Anne G. After Pornified. How women are transforming pornography and why it really matters. Zero Books, 2012

SARMET, Érica Ramos. Pornografia da vulnerabilidade: estratégias feministas de subversão da normatividade pornográfica. In. Imagofagia. n. 18, pag. 545-563, 2018.

Sin porno no hay posporno: corpo, excesso e ambivalência na América Latina. Dissertação (Mestrado) - PPGCOM/UFF, 2015.

SCHECHNER, Richard. Performance Studies. An introduction. 2a edição. NY and London, Routledge, 2006.

SOBCHACK, Vivian. Carnal Thoughts - embodiment and moving image culture. Berkeley and Los Angeles, University of California Press, 2004.

STÜTTGEN, Tim. Post/Porn/Politics. Queer_feminist Perspective on the Politcs of Porn Performance and Sex-Work as Cultural Production. B_Books, Berlim, 2009.

Dossiê Feminismos vitais - https://revistaecopos.eco.ufrj.br/

ISSN $2175-8689$ - v. 24, n. 1, 2021

DOI: 10.29146/ecopos.v24i1.27574 
TAYLOR, Diana. o Arquivo e o repertório. Performance e memória cultural nas Américas. Belo Horizonte, Editora UFMG, 2013.

WILLIAMS, Linda. Hard Core - Power, Pleasure and the "Frenzy of the Visible." Berkeley and Los Angeles: University of California Press, 1989

Dossiê Feminismos vitais - https://revistaecopos.eco.ufrj.br/

ISSN $2175-8689$ - v. 24, n. 1, 2021

DOI: 10.29146/ecopos.v24i1.27574 